\title{
A Study of Micro-lecture Application in College English Teaching
}

\author{
Jia Gao, Chunmei Yu* \\ Public Foreign Language Education College, Beihua University, No \\ 3999 Binjiangdong Road Jilin City, Jilin Province, 132013
}

\begin{abstract}
Micro-lesson is a kind of new way of knowledge transmission and transmission which is based on the Internet. As a new kind of teaching resource, the microcourse provides a wide space for students and college English teachers. The traditional English teaching model of college English teachers' professional ability and business level and the establishment of new teacher-student relationship have certain Impact, has a very important practical significance. Based on the analysis of the current situation of college English teaching and the characteristics of micro-teaching and the teaching function, this paper puts forward the specific thinking of applying micro-curriculum to college English teaching from the aspects of mode design and content selection of college English micro-teaching, Microcurriculum has become a powerful supplement to the current college English teaching, thus promoting the college English teaching. Keywords: micro-lecture, application, college English teaching
\end{abstract}

\section{Introduction}

Micro-course, or micro-curriculum micro-courses, refers to the teaching of video as the main carrier to PPT software as the main technical support, recording teachers around a knowledge point or teaching links to carry out a brief, complete teaching activities. It is to explain a knowledge point as the main task, to short and simple video for the performance of the form, the main content of teaching video, supplemented by teaching design, material courseware, practice testing, peer review. Therefore, the micro-class is not a traditional single teaching 
resource type, but an open, relatively complete and comprehensive new teaching resources. As early as the 1960s, the concept of micro-curriculum was put forward by the affiliated schools of A-hua University in the United States of America, and its research was inclined to the development of short-term courses. Since the 21 st century, more and more attention to foreign micro-video and micro-studies, some into the scale and characteristics of the micro-video affects the world's basic education. In China, the Ministry of Education, Education Technology Association and other micro-courses organized by a series of activities to promote the micro-curriculum in the field of domestic basic education and higher education development. However, the research of microcourse in our country is still at the initial stage, the research direction is mainly macroscopic field, the practice object is concentrated in the basic education stage of elementary and middle school, professional field and applied research in the university are still insufficient.

\section{Analysis of the Features of Micro - courses}

The rapid development of information technology has brought the development of micro-era, WeChat, microblogging, micro-film products such as these microera has entered our lives. It can be said that micro-class also has the microcharacteristics of this micro-era. In the school, the traditional one class takes 40 or 45 minutes, while the micro-class time is short, generally no more than 15 minutes. Today 's college students are not only busy with all kinds of courses in college, but also part - time outside school, to participate in community activities, volunteer activities, it is difficult to find a large time to learn English. Therefore, in the Internet age learn to use micro-time highly effective fragmentation learning is particularly important. No doubt, the micro-time characteristics of micro-class meet this demand.

In the micro-class content, it also reflects the micro-full micro-class in a short span of ten minutes to start a teaching activities around a theme, which requires the subject must be around a subject small knowledge (focus Difficult to doubt) or a simple teaching links. Therefore, the micro-class should reflect its micro, but also pay attention to its essence.Content to refine, the theme should be highlighted, the goal should be clear.

Compared with the traditional slide courseware, the information displayed in the text and graphics is more intuitive and rich. It can also enable the learners to concentrate their attention and improve their learning. Therefore, the teaching mode of situational and visualization not only increases the richness and fun of the content, but also makes it easier for the learners to make the teaching process more flexible and easier to use.

Micro-video video generally smaller capacity, time is short, and the spread of diverse forms, can be easily and easily teaching. Teachers and students can open the Internet to use micro-class resources online, but also can be downloaded directly to the micro-class video to the computer, mobile phone learning. In this way, not only teachers can play in the classroom at any time micro-video 
teaching, and for students, you can play at any time under the micro-video class, but also can repeat the micro-lesson video repeated learning.

\section{The Practical Significance of Micro - courses}

Traditional English teaching model is more single, it is difficult for teachers to stimulate the enthusiasm of college students to learn English. The micro-class with a short time, the characteristics of small micro-classroom, with the help of modern information technology, so that students are fully involved in all aspects of teaching activities, so that learning English as a fun, so as to improve student learning efficiency.

In the traditional teaching process of university, each student's learning ability is different, the classroom often has some students to keep up with the teaching progress. In the college English teaching the introduction of micro-courses, to a greater extent to meet the students for the knowledge of individual, self-learning needs. Micro-class teaching resources provided by the micro-class, microoperation, micro-interaction, micro-detection module built four teaching environment. The use of micro-class not only before and after the class allows students to repeatedly observe, but also can use micro-operations and microtesting, so that the classroom time and space to be extended to facilitate different levels of students to learn English.

For English teachers, it is very difficult to master college English for nursing. However, in the process of micro-course production, English teachers can learn, collaborate and interact with nursing undergraduates. And constantly enrich their knowledge of medical English in order to better qualified professional English course teaching work.

Most of the university students have a weak English foundation, but the goal is to develop a clear English language as a language tool of importance. Traditional English teaching makes the explanation of language knowledge and future workplace separation, students lack sufficient language application situation. It is necessary to introduce microteaching with professional characteristics into college English teaching as a medium between language and majors so that students master the knowledge of English in the vivid context through microoperations, micro-interaction and micro-detection.

\section{The application model and its development trend of micro- class}

At present, the application of microcourse in college English teaching is divided into three modes: the use of micro - class before class, the use of micro - lessons in class and after - school use of micro - class. Before class, students learn microlessons, in advance with the introduction of the new class and focus, difficult to introduce, will preview the effect of maximizing, thereby reducing the teacher to 
explain the time in the classroom. Class, play with the classroom content of the higher degree of micro-class video, teachers can save time and energy, leaving more interaction between teachers and students and classroom activities time. After class, the focus of the classroom difficult to produce short and refined into a micro-class, to the students' image analysis and induction, to improve students mastery of classroom content. The above three application patterns throughout the teaching and learning process, improve classroom teaching efficiency. Nevertheless, the essence of micro-class is still classroom teaching supplement, its main play space is before and after class.

Micro-class allows teachers to have more classroom time and student interaction, to carry out practical activities, to a certain extent, changed the traditional classroom teaching and learning a single relationship and rigid form of knowledge grant. The teacher's classroom dominance will be weakened, more play a guiding role, to guide students how to learn \# to practice using English. At the same time, micro-class to promote self-study before and after school students to change the past passive acceptance of knowledge of the situation, to become active, consciously choose micro-class resources for independent, personalized learning.

From the micro-lessons in China on the date of localization, college teachers in English video produced by the micro-video has two main purposes - to explain the game and a single point of knowledge, such micro-lessons scattered in the classroom and some of the sharing site. They form a variety of content, but independent of each other, not linked to each other, showing a fragmented situation, did not form a complete system and a series of courses, that is, microcurriculum. As the content of English learning, knowledge is fragmented and interrelated. In this regard, I believe that a single fine micro-curriculum should be to the development of micro-courses, the formation of content-related, interrelated, but also independent of each other, with a small amount of exercises exercises. First of all teachers determine the subject of micro-curriculum content, such as cultural explanation, lexical explanation, grammatical point analysis, etc. (and then from the production of a single micro-video, in a specific subject, the production of micro-courses, and gradually build micro-curriculum Practice to form a complete learning system for students to carry out independent individual learning under the curriculum system to form a micro-curriculum in order to attract students to adhere to self-study micro-class, so that micro-learning mode more vitality.

After the formation of a series of micro-micro-courses, teachers put forward higher requirements - to create a micro-learning network platform, the microcurriculum on the platform, sorting, to facilitate students to self-study. Platform in addition to providing online learning, practice and download functions, should be both evaluation, monitoring and surveying and other diversified functions. Evaluation is to provide the correct rate of online exercises to show (monitoring is the teacher in the background through the platform data feedback, that the amount of students on-line and the distribution of learning content in order to understand student learning tendencies, our school learning platform is improving the (Questionnaires can be an additional function of the English learning platform, 
set up a questionnaire, teachers can be collected on the platform curriculum design, teaching feedback, student thought dynamic and other content of the questionnaire.Micro class and learning platform is a mutual integration, Complement each other's relationship.Excellent and adequate micro-class resources presented in the online learning platform to promote the use of learning platform for students in order to make learning platform for other functions to be used.At the same time, convenient and good platform for students to use more fun The above micro-lesson resources.

The systematization of microcourse is the resource base for creating the microcourse platform, and the platform-based development of microcourse can promote the sharing of resources. English micro-production of many content, the effort can not be underestimated, not one or a group of teachers to complete the independent. Only the major universities to create an open English learning platform, and teachers and students outside the school to share high-quality English micro-class resources, we work together to share resources and complement each other in order to enrich and improve micro-curriculum, to maximize the sharing of resources, and even the most optimization.

\section{Conclusion}

A series of micro-learning and English micro-curriculum into the learning platform, all this is the use of micro-teaching teachers this new learning aided model, so that college English teaching more dynamic, closer to today's students learning habits, Students can more effectively carry out autonomous English learning. Only the front-line teachers work together to create or collect more excellent micro-class resources, integration and improvement, the formation of the system (only more teachers to participate in micro-class research and development, theoretical research, in order to continuously improve and develop micro- In order to make this new thing micro-class full of vitality, in college English teaching have a good influence.

\section{Acknowledgements}

The research work was supported by [2015] 75: Education and Science Project, Jilin Contract. NO. 104115003

\section{References}

[1] Liu Jirong. Rational use of media technology, the effective creation of teaching situations. China Science and Technology Innovation Guide. 55(12), pp.68-70, 2011 
[2] Jiang Huilin. Cases of multimedia technology in junior high school English teaching in the use. Foreign language learning (middle school version of the late.) 8 (5), pp.87- 91, 2013

[3] Zheng Xian. "Magical" multimedia, extended English teaching. Middle School English Garden. 12(10), pp. 18- 20, 2012

[4] Li Xincui. Application of multimedia technology to create English teaching situation. Journal. 9(6), pp.58- 61, 2011

[5] Fu Riqing. English teaching in junior high school under the network environment. New Course (middle). 8(4), pp.85-87, 2014 